\title{
The Monte Carlo Method in Nuclear Medicine: Current Uses and Future Potential
}

$\mathbf{I}_{\mathrm{f}}$

f one could predict the exact path that a photon, electron, or $\alpha$-particle might follow and the energies these particles retain as they traverse different tissue regions of the body, one could calculate many useful quantities by averaging over a very large number of particle histories, defined as the total experience a particle undergoes from the time it is emitted to the time it is absorbed or passes from a region of interest. This concept of using a large number of particle histories, each of which is random in nature, to estimate the average behavior of the particle group is the essential feature

See page 462

of the Monte Carlo method-a class of computational algorithms that rely on repeated random samplings to compute physical quantities (l).

One of the first conceivers of the Monte Carlo method was Stanislaw Ulam, a Polish mathematician who participated in the Manhattan Project and originated the Teller-Ulam design for thermonuclear weapons. The idea occurred to him in 1946 when he was convalescing from an illness and was playing solitaire. The question he posed was what are the chances that a Canfield solitaire laid out with 52 cards will come out successfully? "After spending a lot of time trying

Received Nov. 25, 2009; revision accepted Dec. 2, 2009.

For correspondence or reprints contact: Wesley E. Bolch, University of Florida, 202 NSC, Gainesville,

FL 32611-8300.

E-mail: wbolch@ufl.edu

COPYRIGHT (c) 2010 by the Society of Nuclear Medicine, Inc.

DOI: 10.2967/jnumed.109.067835 to estimate them by pure combinatorial calculation, I wondered whether a more practical method... might not be to lay it out say one hundred times and simply observe and count the number of successful plays. This was already possible to envisage with the beginning of the new era of fast computers, and I immediately thought of problems of neutron diffusion and other questions of mathematical physics, and more generally how to change processes described by certain differential equations into an equivalent form interpretable as a succession of random operations. Later...[I] described the idea to John Von Neumann and we began to plan actual calculations." (2). John Von Neumann was himself a pioneer of operator theory and quantum mechanics, a principal member of the Manhattan Project. Both Von Neumann and Ulam applied the new technique to the problem of neutron penetration distance and resultant energy loss in various engineering materials. Essentially, they ran experiments on Los Alamos computers and sought their solutions through following many individual neutrons along their histories. This being a secret governmental project, Von Neumann needed a code name for the technique. He chose as his reference the Monte Carlo Casino in Monaco where his uncle was a loyal patron (3).

And so it is with the early beginning of nuclear medicine dosimetry. With the design of the first mathematic model of the human body, Walter Snyder at the Oak Ridge National Laboratory used the Monte Carlo method to track $\gamma$-rays and $\mathrm{x}$-rays from radionuclides within various source tissues and assess the fraction of their emitted energy that is locally deposited in various target tissues (4). This ratio of energy absorbed to energy emitted was the absorbed fraction defined within the newly conceived MIRD method of internal dosimetry (5). Values of specific absorbed fraction-ratio of the absorbed fraction to the target tissue mass-were tabulated by Snyder et al. for a wide variety of source and target tissue combinations in International Commission on Radiological Protection publication 23 on reference man (6) and were later used to calculate and tabulate the initial values of radionuclide $\mathrm{S}$ values (absorbed dose per nuclear transformation) in MIRD pamphlet no. 11 (7). In 1980, researchers Cristy and Eckerman introduced a revised series of mathematic phantoms (8), and in 1987, they reported an extended series of specific absorbed fractions-obtained through the Monte Carlo methods-for their adult and pediatric phantom series (9). These values now form the basis for the popular MIRDOSE and OLINDA codes $(10,11)$. During the development of ORNL/TM-8381 (9), some 60,000 monoenergetic photon histories were simulated, a value limited by computer resources of that time. Today, more complex and anatomically realistic phantoms are used in phantom-based assessments of absorbed fractions and radionuclide $\mathrm{S}$ values, using between 1 and 100 million photon histories. The Monte Carlo method finds its application in assessing radionuclide $\mathrm{S}$ values in animal models for radiopharmaceutical preclinical testing (12-14), for patient-specific modeling of radionuclide therapies $(15,16)$, and for generating simulated 3-dimensional images via SPECT or PET $(17,18)$. 
In this issue, authors Zhongli Cai et al. from Toronto have invoked the Monte Carlo method, and the Monte Carlo N-particle radiation transport simulation code (version 5), to reevaluate ${ }^{111}$ In $S$ values for subcellular distributions for both the self-dose and the cross-dose terms (19). In particular, new values of cellular $S$ values were determined for a monolayer of cells as would be the case for in vitro experiments. Previous studies had considered only single isolated cells or 3-dimensional cell clusters in the tabulation of cellular $\mathrm{S}$ values via analytic techniques. After a series of benchmark simulations, the authors used their newly established $\mathrm{S}$ values-derived uniquely for cellular and nuclear dimensions for specific cell lines-to make predictions of cell survival in comparison to experimental values. In this study, breast cancer cells were exposed in vitro to ${ }^{111} \mathrm{In}$ labeled diethylenetriaminepentaacetic acid human epidermal growth factor (20). The results confirmed the application of Monte Carlo radiation transport simulation to generation of cellular $S$ values that are unique to specific cell lines in the preclinical development of new radionuclide therapies. The authors noted that in many experimental systems, one needs to be able to move away from both analytic methods of dosimetry and idealized concentric sphere models of the cell and cell nucleus, to consider asymmetric nuclei and nonspheric cell shapes as in the case of a monolayer cells in culture. The Monte Carlo method allows one to fashion a geometric simulation environment uniquely tailored to the experimental system at hand.

Although this unique study uses the Monte Carlo method to assess the absorbed dose to the nucleus in Auger electron radiotherapies targeting peptide receptors, the method may potentially be extended to better understand the mechanistic actions of this localized energy deposition. Energy lost by Auger electrons may induce direct damage to nuclear DNA but will more prominently result in the ionization and excitation of water molecules adjacent to or within the hydration layer of DNA. Studies funded in the 1980s by the U.S. Department of Energy resulted in the development of many unique Monte Carlo codes capable of following electrons and $\alpha$-particles at molecular spatial dimensions, with subsequent modeling of the events interlinking the physics of particle energy loss and production of free radical species $\mathrm{OH} \cdot, \mathrm{H} \cdot$, and $\mathrm{e}_{\mathrm{aq}}$ (the hydrated electron) $(21,22)$. Once these free radical species are formed, Monte Carlo methods can be further used to simulate their molecular diffusion and intratrack chemistry (23), as well as chemical interactions with the sugar (24) and base moieties of DNA (25). Ultimately, it is this level of radionuclide therapy modeling that will give us a full understanding of the therapeutic potential for intracellular radionuclide targeting strategies for cancer therapy. Many of these codes, however, have not been maintained, and new funding for their development should be established. Just as radionuclide therapy is progressing from phantom-based organ dosimetry to patient-specific organ dosimetry via the Monte Carlo method of particle transport, preclinical in vitro studies may see the need for cell-specific dosimetry using the best features of molecular imaging (to determine cell-specific radionuclide uptake) and molecular radiation transport (to determine cell-specific molecular damage).

\section{Wesley E. Bolch \\ University of Florida \\ Gainesville, Florida}

\section{REFERENCES}

1. Shultis J, Faw R. Radiation Shielding. La Grange Park, IL: American Nuclear Society; 2000.

2. Eckhard R. Stan Ulam, John Von Neumann, and the Monte Carlo Method. Los Alamos Sci. 1987; 15:131-136.

3. Grinstead CM, Snell JL. Introduction to Probability. Providence, RI: American Mathematical Society; 1991.

4. Snyder WS, Ford MR, Warner GG, Fisher HL. Estimates of Absorbed Fractions for Monoenergetic Photon Sources Uniformly Distributed in
Various Organs of a Heterogeneous Phantom. New York, NY: Society of Nuclear Medicine; 1969. MIRD pamphlet no. 5.

5. Loevinger R, Berman M. A formalism for calculation of absorbed dose from radionuclides. Phys Med Biol. 1968;13:205-217.

6. International Commission on Radiological Protection. Publication 23: Report on the Task Group on Reference Man. Oxford, U.K.: Pergamon Press; 1975.

7. Snyder WS, Ford MR, Warner GG, Watson SB. MIRD Pamphlet No. 11: S, Absorbed Dose per Unit Cumulated Activity for Selected Radionuclides and Organs. New York, NY: Society of Nuclear Medicine; 1975. MIRD pamphlet no. 11.

8. Cristy M. Mathematical Phantoms Representing Children of Various Ages for Use in Estimates of Internal Dose. Oak Ridge, TN: Oak Ridge National Laboratory; 1980. ORNL/NUREG/TM367

9. Cristy M, Eckerman KF. Specific Absorbed Fractions of Energy at Various Ages from Internal Photon Sources. Oak Ridge, TN: Oak Ridge National Laboratory; 1987. ORNL TM8381.

10. Stabin MG. MIRDOSE: personal computer software for internal dose assessment in nuclear medicine. J Nucl Med. 1996;37:538-546.

11. Stabin MG, Sparks RB, Crowe E. OLINDA/EXM: the second-generation personal computer software for internal dose assessment in nuclear medicine. J Nucl Med. 2005;46:1023-1027.

12. Stabin MG, Peterson TE, Holburn GE, Emmons MA. Voxel-based mouse and rat models for internal dose calculations. J Nucl Med. 2006;47: 655-659.

13. Padilla L, Lee C, Milner R, Shahlaee A, Bolch WE. Canine anatomic phantom for preclinical dosimetry in internal emitter therapy. J Nucl Med. 2008;49:446-452.

14. Larsson E, Strand SE, Ljungberg M, Jonsson BA. Mouse S-factors based on Monte Carlo simulations in the anatomical realistic Moby phantom for internal dosimetry. Cancer Biother Radiopharm. 2007;22:438-442.

15. Dewaraja YK, Wilderman SJ, Ljungberg M, Koral KF, Zasadny K, Kaminiski MS. Accurate dosimetry in ${ }^{131} \mathrm{I}$ radionuclide therapy using patient-specific, 3-dimensional methods for SPECT reconstruction and absorbed dose calculation. J Nucl Med. 2005; 46:840-849.

16. Prideaux AR, Song H, Hobbs RF, et al. Threedimensional radiobiologic dosimetry: application of radiobiologic modeling to patient-specific 3-dimensional imaging-based internal dosimetry. J Nucl Med. 2007;48:1008-1016.

17. Holstensson M, Hindorf C, Ljungberg M, Partridge M, Flux GD. Optimization of energy-window settings for scatter correction in quantitative ${ }^{111} \mathrm{In}$ imaging: comparison of measurements and Monte Carlo simulations. Cancer Biother Radiopharm. 2007;22:136-142.

18. He B, Du Y, Segars WP, et al. Evaluation of quantitative imaging methods for organ activity and residence time estimation using a population of phantoms having realistic variations in anatomy and uptake. Med Phys. 2009;36:612619.

19. Cai Z, Pignol J-P, Chan C, Reilly RM. Cellular dosimetry of ${ }^{111} \mathrm{In}$ using Monte Carlo N-particle computer code: comparison with analytic methods and correlation with in vitro cytotoxicity. $\mathrm{J} \mathrm{Nucl}$ Med. 2010;51:462-470. 
20. Bailey KE, Costantini DL, Cai Z, et al. Epidermal growth factor receptor inhibition modulates nuclear localization and cytotoxicity of the Auger electron emitting radiopharmaceutical ${ }^{111}$ In-DTPA human epidermal growth factor. J Nucl Med. 2007;48:1562-1570.

21. Turner JE, Hamm RN, Wright HA, et al. Studies to link the basic radiation physics and chemistry of liquid water. Radiat Phys Chem. 1988;32:503-510.
22. Dingfelder M, Ritchie RH, Turner JE, Friedland W, Paretzke HG, Hamm RN. Comparisons of calculations with PARTRAC and NOREC: transport of electrons in liquid water. Radiat Res. 2008; 169:584-594.

23. Turner JE, Magee JL, Wright HA, Chatterjee A, Hamm RN, Ritchie RH. Physical and chemical development of electron tracks in liquid water. Radiat Res. 1983;96:437-449.
24. Aydogan B, Marshall DT, Swarts SG, et al. Sitespecific $\mathrm{OH}$ attack to the sugar moiety of DNA: a comparison of experimental data and computational simulation. Radiat Res. 2002; 157:38-44.

25. Aydogan B, Bolch WE, Swarts SG, Turner JE, Marshall DT. Monte Carlo simulations of sitespecific radical attack to DNA bases. Radiat Res. 2008;169:223-231. 